\title{
Consumers and their behavior: state of the art in behavioral science supporting use phase modeling in LCA and ecodesign
}

\author{
Eugenia Polizzi di Sorrentino ${ }^{1} \cdot$ Eva Woelbert $^{1} \cdot$ Serenella Sala $^{2}$
}

Received: 19 February 2015 / Accepted: 18 December 2015 / Published online: 7 January 2016

(C) The Author(s) 2016. This article is published with open access at Springerlink.com

\begin{abstract}
Purpose Life cycle thinking and assessment require a holistic approach to the evaluation of product supply chains. An assessment from raw material extraction to end of life of any products is based on modeling a wide number of aspects and options, e.g., at technological, geographical, and temporal levels. Since the use phase is one of the most contributing life cycle stages for some products (e.g., appliance, housing, cars), a robust modeling of this stage is fundamental. Several attempts to better modeling use-phase have been performed; however, so far no systematic study is available on how to integrate behavioral science (BS) insights into LCA. This is even more important when the impact of the product under consideration is strongly determined by the use phase relatively to other life cycle stages. The aim of this paper is to explore how behavioral science has been used to date and how BS can contribute towards more robust modeling of use phase in LCA and as basis for a behavior-driven ecodesign.

Methods We identified the key areas in which LCA and ecodesign may benefit from integrating insights from behavioral science and developing a conceptual model. Both robust modeling and the design of behavior change interventions rest
\end{abstract}

Responsible editor: Alessandra Zamagni

Serenella Sala

Serenella.sala@jrc.ec.europa.eu

1 European Commission, Joint Research Centre, Institute for Health and Consumer Protection, Public Health Policy Support, Behavioural Economics Team, Via Enrico Fermi 2749, 21027 Ispra, VA, Italy

2 European Commission, Joint Research Centre, Institute for Environment and Sustainability, Sustainability Assessment Unit, Via Enrico Fermi 2749, 21027 Ispra, VA, Italy on a sound understanding of behavior in the specific context of interest though empirical investigation. Hence, we reviewed literature on behavioral science and introduce key drivers of human behavior that are relevant in the context of use phase modeling and ecodesign. We provide examples where these were applied to facilitate the integration of BS elements by practitioners.

Results and discussion Consumer's behavior is increasingly recognized as one of the drivers of overall environmental impact of a product, and some examples of use of BS for LCA are available in literature. We suggest that behavioral science can be useful in the context of life cycle assessment in two ways: measuring behavior and assessing potential and means for changing behavior. Specifically, insights and methods from behavioral sciences could be applied for assessing variability of consumer behavior, understanding leverages for behavioral changes, and possible rebound effects.

Conclusions This insight may help to model the use phase more accurately, to identify realistic scenarios, and to support behavior-driven eco-innovation.

Keywords Consumer behavior - Behavioral economics · Life cycle assessment $\cdot$ Life cycle thinking $\cdot$ Sustainability science . Use phase

\section{Introduction}

In the environmental impact assessment of a product, behavioral aspects play a role in the choice between different alternative products, the subsequent behavior of the consumer in using the product, and - at the end of the use phase - in the decision how to dispose of the product. The environmental profile of a wide range of products is affected by one or several of these behavioral factors, for example, in terms of 
energy and resource use, emission release and waste production (Peattie 2010). Several life cycle assessment (LCA) studies present a contribution of the use phase at the level of 50$80 \%$ of the overall life cycle impacts (e.g., household electric device, Hertwich and Roux 2011). This means that variation in use phase may greatly impact the overall results and the uncertainties thereof. Nevertheless, behavioral aspects tend to be less modeled in methodologies such as LCA. That is, even though LCA allows the definition of scenarios related to the use phase, the modeling of the different options and the potential variability of impacts thereof are usually based on basic assumptions. Among the challenges for the future development of LCA, including consumer behavior in use phase modeling is considered crucial (Hellweg et al. 2014).

Modeling the use phase accurately depends on a good understanding of actual user behavior. Behavioral science provides a set of sound empirical methods to investigate behavior from a quantitative point of view, that can be flexibly employed depending on resources available and the type of information needed. Whenever the use phase is relevant, interventions aiming to change behavior in the use phase can be a powerful way to decrease the environmental impact of a product. The accumulated knowledge about behavior and the factors affecting it may further help eco-designers to redesign products that are more likely to be used in the desired way. The integration of the behavioral component and modeling the opportunity for behavioral change into LCA studies could make the difference when dealing with the impact of products both on the environmental and human health-related domains (Cohen et al. 2010; Tukker et al. 2010). Indeed, how closely the estimated use in LCA studies resembles the reallife situation-beyond average use-phase parameters or assumption based on laboratory test-is still unclear (Daae and Boks 2015).

For example, studies modeling the environmental impact of replacing animal-derived food with plant-based food (Westhoek et al. 2014) could be informed by behavioral insights in two ways: first of all, behavioral studies can provide a more realistic bound to the extent to which dietary habits can be changed in the short run. Second, behavioral studies can provide insights on what policies may be more effective in achieving these changes, especially in the face of cultural heterogeneity and the cultural importance of food. An example of the use of behavioral science methodology in environmental policy is a study recently conducted for the Directorate General Environment of the European Commission in order to understand how to successfully communicate information about the environmental profile of products to consumers (BIO Intelligence Service 2012).

Recognizing that behavior in the use phase is an important aspect of the overall impact of a product, it is evident that including the behavioral component into life cycle assessment can be useful. The aim of this paper is, therefore, to present a way towards more robust and systematic modeling of use phase in LCA using tools and insights coming from behavioral science. In the following, we present an overview of current practices in modeling the use phase in LCA. The remainder of the paper discusses different psychological theories about behavior and behavior change that are potentially relevant for LCA studies (Section 3); Section 4 illustrates some of the methodological tools commonly used in behavioral studies to observe and predict behavior, and explores their potential for modeling more realistic scenarios of user behavior. Sections 5 presents some of most central topics in behavioral science and their implications for behavior change with regard to LCA and eco-design. Building on the previous sections, we present a conceptual model of how to integrate behavioral science with LCA (Section 6). The paper concludes discussing the potential limitations of the integration of behavioral science into the LCA context.

\section{Modeling use phase in LCA: overview of current practices and needs}

Energy-using appliances were among the first for which the use phase has been explicitly modeled, presumably due to the fact that a relatively high share of environmental impact is generated during the use phase, rather than during production phase (Throne-Holst et al. 2007). Beyond appliances, a similar conclusion has been drawn for products that consume energy in any form during use or transform chemically during application (Hanssen 1998). For example, use phase was also considered in early LCA studies on cars. Eberle and Franze (1998) were among the first to model the use phase of cars and identified relevant parameters of a vehicle's use phase for life cycle inventory. Other studies investigated the relevance of the use phase in the environmental profile and carbon footprint of detergents where consumer use phase is also crucial (Saouter et al. 2002; Koehler and Wildbolz 2009). Moreover, the results of Johnsson's (1999) LCA studies on the emission of organic compound in different types of floor coverings demonstrate that the inclusion of typical user behavior (e.g., cleaning) greatly changed the overall environmental profile of specific floor materials (e.g., wood), highlighting also some potentially negative health effects for consumers. Realizing its importance, LCA studies now typically attempt to model the use phase explicitly. From an LCA perspective, different behaviors occurring in the use phase may lead to different intensities of the impacts. As long as the identification of impactful behaviors, as well as their relative weight in representing different user scenarios (e.g., how frequent is that specific behavior with that specific product) is not well modeled, it will be difficult to understand which behavior (or combination of, as in specific user scenarios) is potentially most impacting within the use phase. 
Nevertheless, in the estimation of the actual impact of the use phase, LCA studies often rely on aggregated, secondary data sources or straightforward assumptions that greatly limit the accuracy (see Daae and Boks 2015). For example, in a previous LCA study comparing the impact of modern vs old wooden ovens, the use phase was found to be responsible for over $60 \%$ of the overall environmental impact (Solli et al. 2009). However, the efficiency of burning stoves is greatly affected by the burning practice of users and the maintenance of the stove. This underlies that changing the parametrization of user behavior would possibly lead to different impacts of the use phase. In the absence of any behavioral data on these parameters, emissions (e.g., impact) were calculated on the basis of an assumed efficiency (Solli et al. 2009). However, the authors also acknowledge that the absolute levels of emissions are greatly sensitive to changes in efficiency. Thus, a more accurate estimate of efficiency, taking into account also wood burning and maintenance habits, could increase the accuracy of the LCA.

Several studies have highlighted the need to go beyond simple averages in modeling the use phase and to account for inter-individual behavioral variation by modeling different usage scenarios (e.g., Reinhart 2004; Yun et al. 2009; Haldi and Robinson 2011; Langevin et al. 2015). O'Brien et al. (2009) tried to overcome the limitation of average usage patterns by including three different usage scenarios in an LCA study comparing different types of nappies. The scenarios (high, medium, low) accounted for the highest and lowest values for nappy weight, usage rates, and (reusable) nappies lifespan. Although the inclusion of different scenarios greatly increased the opportunity for identifying conditions for the lowest environmental impact of the product, some values were based not on behavioral data of actual use but on "best practices" (e.g., water and energy consumption for washing and drying behavior) making it difficult to understand to which extent they reflect the actual practice of the users.

Modeling variation in the use phase, as was done in the example on nappies above, can not only help to paint a more realistic picture of the use phase but it can also highlight the potential for improvement in the environmental impact of a product through behavior change. For example, Woolridge et al. (2006) quantify the relative impact of recycled vs virgin cotton clothes, showing that recycling behavior successfully reduces the environmental burden of clothing. The effect of recycling behavior on the impact of clothes may become especially relevant if such behavior represents a high share of a possible user scenario. However, the final impact might be also affected by the occurrence of rebound effects (e.g., recycling clothes may save money that could be reinvested in buying more clothes; buying recycled clothes might not be substitutive for new clothes, but rather additive). This example illustrates how important it is take into account possible spillover effects when modeling the use phase, and that the implications for LCA depend on whether rebound effects are tackled in a more narrow sense, i.e., for one functional unit of the good (e.g., individual usage patterns or direct rebound effects resulting in a different intensity of use of an appliance) or in a broader sense, i.e., including effects on demand, also for other goods. In fact, rebound effect assessment is another area in which LCA studies has been focused. A recent review by Vivanco and van der Voet (2014) highlights how central is behavioral science for proper modeling direct and indirect rebound effect.

As LCA is used both for assessing environmental profile of products and for identifying elements for improving products, it may help steering ecoinnovation and ecodesign towards impact minimization. For example, there is a recent study by Daae and Boks (2015) in which the authors review how behavior insights have been use in design for sustainable behavior (DfSB), complementing LCA studies.

The following sections delve into how BS observe, measure, and assess behavior including potential of behavior change in order to build a conceptual framework for the integration between behavioral science, LCA, and ecodesign.

\section{Relevant concepts in behavioral science}

The topic of environmentally relevant behavior has been subject of study by various academic disciplines, including psychology, economics, sociology, and design. There is a strong trend towards interdisciplinary in the study of human behavior. Especially insights from psychology are used by various other disciplines to enhance their understanding. Although some differences remain between disciplines both in scope and in methodology, the term "behavioral science" is useful to summarize various efforts to describe, understand, and change behavior. In the following, we will focus on concepts from economics and psychology that we could support the integration of BS in the context of LCA. An in-depth review of the literature on sustainable behavior is given by Jackson (2005).

A familiar assumption, which has guided much of existing policy until today, is that consumers behave as "rational decision makers", analyzing all available pieces of information in ways that always optimize their best interests, weighing the cost and the benefit of each option. Traditional economic theory is largely agnostic about what these costs and the benefits are specifically, but assumes that decision makers maximize their net utility in a consistent fashion.

Traditional psychological theories of behavior and behavior change, on the other hand, have sought to fill the model of the decision maker with content and have devised a large number of different models describing what influences decisions and behavior. Historically, psychological models focus on factors internal to the individual, such as attitudes and 
beliefs, as determinants of behavior. One prominent example is the theory of planned behavior (Ajzen 1991). This theory postulates that behavior is the result of intentions, which in turn is determined mainly by attitudes, beliefs about what is the social norm, and perceived behavioral control. Notably, this theory has received substantial empirical support across a wide range of behaviors also outside the environmental realm. That is, researchers have found that measurements (e.g., via a questionnaire) of attitudes, beliefs, and perceived behavioral control regarding a specific behavior are good predictors of intentions to perform this behavior, which in turn is a (weak) predictor of this behavior occurring in the future (Armitage and Conner 2001; Bamberg and Möser 2007). However, the validity of the theory of planned behavior and similar models has been criticized as limited due to the focus on conscious internal variables (attitudes, values, beliefs) and the omission of other important aspects (Jackson 2005). Some studies on environmental behavior have therefore used more comprehensive models such as Triandis' model (Triandis 1977; Bamberg and Schmidt 2003) or the comprehensive action determination model (CADM; Klöckner and Blöbaum 2010). These integrate also habits and external factors, such as situational conditions, thus arriving at a more complete picture and better predictive validity. It should be noted, however, that many studies evaluating these psychological models in the environmental realm, although predictively studying behavior, are still correlational in nature (Jackson 2005).

At the same time, research efforts at the intersection of economics and psychology (often referred to as behavioral economics) have challenged the rational actor model through observations of human behavior in highly controlled experiments, and have made progress to understand the basic processes underlying human decisions. Various robust behavioral phenomena have been identified that are inconsistent with the rigid rationality assumptions. These behavioral patterns, which are not in line with the traditional model of the human decision maker as a rational actor, are often called "irrationalities" or "biases" (Tversky and Kahneman 1974, 1981). They are of interest because they reveal fundamental properties of human decision making as well as predictable mistakes. A second assumption that is frequently made in traditional economic analyses of behavior is that humans are fundamentally selfish. A rich theoretical and experimental literature exists that analyses human interaction in social situations and identifies important drivers of non-selfish behavior (Fehr and Fischbacher 2004).

Interest in the study of human decision making has increased remarkably in the past decade, and new fields such as human decision science or neuro-economics have emerged. In parallel with this increase in academic interest, it has also been recognized that understanding human decision processes has important implications for public policy (Thaler and Sunstein 2008). This is also true for policies related to sustainable behavior (Bamberg et al. 2011; Ölander and Thøgersen 2014), which is reflected in a number of articles and survey papers (Gowdy 2008; Shogren and Taylor 2008; Peattie 2010; Carlsson and Johansson-Stenman 2012; Hammitt 2013; Croson and Treich 2014).

In the context of LCA analyses, where knowledge of how people behave would be central, the strong focus of behavioral scientists on explaining behavior probably means that the models outlined above are themselves of limited use. This is especially true since it has been found that asking people directly for their behavioral intentions is still a better predictor of behavior than the presumed determinants such as attitudes and beliefs (Webb and Sheeran 2006). Nevertheless, we argue that behavioral science can be useful in the context of LCA in two ways: First of all, as will be detailed in Section 4, the necessity of the behavioral sciences to observe behavior means that various methods to measure intentions and behaviors are available. Second, understanding the drivers of behavior can also be a useful guidance for those wishing to design products or interventions that lead to behavioral change (Jackson 2005; Zachrisson and Boks 2012a; Zachrisson Daae and Boks 2014). That is, new products or interventions can be developed (and again tested with LCA) so that they specifically target the determinants of behavior postulated by the theory, be it psychological such as attitudes towards a certain behavior or situational such as which option is most convenient. In Section 5, we therefore highlight important behavioral aspects and recent interesting studies on sustainable behavior with a focus on behavior change.

\section{Observing, measuring, and predicting behaviors}

From an LCA perspective, the way in which users interact with products may be responsible for a significant share of the total environmental impact generated during products life cycle. Interactions between users and products (e.g., product use) may be subjected to a considerable variation, and this may have a large effect on the overall results of LCA studies. Despite some attempts to categorize the causes of such "uncertainty" in how products are used and the possible consequences within LCA (Huijbregts 1998), variability in the use phase is often neglected, and parameters are generally based on secondary data source or on assumptions that are not necessarily reflecting the range of users' behavior in real life. In order to support the use phase modeling, it is crucial to understand how to observe, measure, and predict behaviors.

\subsection{Observational methods in behavioral science for assessing variability in user behaviors}

Behavioral scientists possess a variety of tools to arrive at precise observations of behavior and other relevant variables. 
While the purpose of many studies in environmental psychology and related fields is undoubtedly to understand the driving factors of sustainable behavior, the employed research methods can be equally useful to observe and describe the behavior as such. Many studies in environmental psychology and related fields rely on self-reported behavior in the form of surveys. With surveys, researchers may access a large sample of people and question them not only about their behavior but also about psychological variables such as their attitudes, beliefs, and expectations. Surveys allow for a high degree of external validity, in the sense that they capture how people think "out there". However, the way a questionnaire is designed is important and may substantially affect the findings. Significant research efforts have been made towards the development of empirically validated questionnaires for specific variables of interest, such as intentions to perform a specific behavior or attitudes towards the environment. As a result, several probed questionnaires are available in the literature (e.g. Milfont and Duckitt 2010; Klöckner and Blöbaum 2010).

Surveys are particularly interesting in the context of a LCA, because variables that can be assessed by means of a questionnaire can typically be gathered on a large enough scale to be representative of the population of interest. For example, Laitala et al. (2012) employed representative surveys to assess how people use and maintain their clothes. Moreover, several large-scale projects exist that regularly survey representative samples and make data accessible for other researchers free of charge (e.g., Eurobarometer surveys). Thus, in principle, surveys can allow LCA researchers to get some indication of the types of user behavior (and their distribution) in the general population.

A potential downside of surveys is that they often measure only intention but not the actual behavior. This is particularly relevant in the context of sustainable behavior where people are likely to provide socially acceptable answers, rather than the truth. Moreover, research has shown that thinking "green" is often not the same as acting "green" (Davies et al. 2002; Pickett-Baker and Ozaki 2008). Possible reasons for this include the fact that people tend to overstate their engagement in behaviors that are socially desirable (see for example Nederhof 1985), which is the case for environmentally relevant behaviors or - when people are asked to report about past behavior - simply memory problems (Corral-Verdugo 1997). For example, the answers collected from a recent Eurobarometer survey containing questions such as "In the past month, have you separated most of your waste for recycling" from representative samples of all European Union member states (Special Eurobarometer 416) might be more informative on how people like others to see them, rather than on actual behavior.

Therefore, significant efforts have been made to develop more direct tools to measure behavior, which is facilitated by the advent of new technologies. Modern communication technology allows for example to prompt users repeatedly during the measurement period to answer questions about current (or recent) behavior (Shiffman et al. 2008; Klöckner and Blöbaum 2010). Although still relying on self-reported behavior, the repeated sampling minimizes biases due imperfect recall and is more accurate.

Rapid developments in sensor technology and computing power further allow observing behavior directly on a larger scale. Smartphones, for example, now contain GPS sensors as well as accelerometers, which collect detailed information about physical activity and transportation (Zafiroglu et al. 2012). Logan and Healey (2006) describe how activities of daily living can be classified by sensors, and the vision of the internet of things described for example in (Gubbi et al. 2013) suggests that detailed large-scale data on user behavior of appliances such as fridges and washing machines might be available soon. Many research facilities now possess facilities to create virtual environments and observe or model the behavior of humans in the interaction with a very specific and controlled environment, which may be interesting for testing new designs in the form of a digital prototype (Gabbard and Swan 2008; Carsten and Jamson 2011; Bennadji et al. 2015).

While for now direct observation of behavior is typically too costly and cumbersome to perform on a scale that is representative of the general population, data from relatively small samples can still provide the required information to determine the characteristics of main user scenarios (e.g., average, upper or lower bound) realistically or at least to make a judgment whether current assumptions are reasonable (Scott 2005). Moreover, direct observation of a small sample can be combined with a representative survey, which is more suited to arrive at accurate estimates of the distribution in the population. Combining the two can help in the development of relevant survey questions, which can then allow extrapolating what is seen in direct observations of behavior to a larger scale (Falk et al. 2013).

\subsection{The assumption of constant demand, behavioral spillover, and rebound effects}

One important assumption about the use phase in LCA concerns the possibility for behavioral spillover or rebound effects. That is, environmental impacts of a product may not only be generated by the product itself, and the use of the product, but also by a change in user behavior that occurs as a consequence of one or several attributes of the product (Hertwich 2005; Hofstetter et al. 2005). According to Vivanco et al. (2015), who analyzed how rebound effect has been modeled in several LCA case studies, consumer behaviors are central elements for assessing direct and indirect rebound effects, whereas market and economic behaviors are used for structural and transformational rebound effects. 
It has long been acknowledged that product attributes can lead to changes in behavior and demand. A famous example of such indirect effects is the change in consumption that can occur if more household income is available, e.g., because a product is cheaper than another or because more energyefficient appliances lower the overall household energy expenditure. Money is not the only scarce resource that can mediate changes in consumption: Time, space, and skills have been suggested, among others, to bear the potential to affect consumption (Hofstetter et al. 2006). For example, if certain time-consuming activities such as transportation become faster, more time becomes available to do either more of the same (e.g., travel to more places, see Chen and Mokhtarian 2006) or more of something else. This effect is also thinkable for fairly small but frequent actions, such as making coffee with a more automatized coffee machine.

Demand changes can not only result from changes in money or time budgets but have also been described in the behavioral literature as a result of interventions (Truelove et al. 2014; Dolan and Galizzi 2015). For example, an intervention designed to lower water consumption was effective at achieving this goal, but at the same time increased energy consumption (Tiefenbeck et al. 2013). Likewise, if people perceive a product as more environmentally friendly, they may be likely to use it more. On the other hand, they may instead feel motivated to use it in a resource efficient way or reduce energy consumption with other products as well (Lanzini and Thøgersen 2014; Steinhorst et al. 2015). Thus, both positive and negative spillover effects of intervention are thinkable.

As outlined by Girod et al. (2011), such indirect effects are incompatible with the frequently made assumption that demand will be constant across different products that are compared within an LCA study. For example, Humbert et al. (2009) compare different preparation modes for one cup of coffee. Given that preparing capsule espresso coffee is very convenient, the availability of a capsule espresso machine may well alter demand. Likewise, if one product is cheaper than another, this frees up household income for other potentially impactful consumption. As long as the comparison is made on equally sized functional units, such differences are neglected. Girod et al. (2011) suggest modeling the change in consumption directly, for example by assuming that households will simply consume more of what they already consume.

Again, in order to model behavior accurately, it is useful to support these assumptions by an understanding of how people actually respond to increased access to faster services or more income, and observational data can be used in order to inform estimates. For example, Thiesen et al. (2008) suggest that presumably not all households will respond in the same way to a marginal increase in income, but their response may be dependent on characteristics such as their income level. Therefore, estimating changes in demand from aggregate, e.g., country-level, data may be inaccurate. They then use data from household expenditure surveys to estimate separately for different levels of income how a small change in income might affect consumption (Thiesen et al. 2008). This allows for a more precise estimation of the environmental impact generated by the additionally disposable household income. As illustrated by Thiesen et al. (2008), this effect can be substantial.

\section{Understanding behavior for promoting behavioral changes}

Besides providing means of assessing the overall environmental impact of a certain product, LCA also offers a valid methodology to investigate the potential for targeting ecoinnovation towards impact reduction. LCA studies are often used as a basis for ecodesign, testing several options and helping identifying product hotspots to be addressed. When the hotspots of the impacts are associated to use phase, the role of user's behavior becomes crucial.

Coupling LCA with behavioral science may result in informing product designers and/or policy makers about both the feasibility of the envisioned behavioral modification, as well as about the possible ways through which behavior change could be achieved. In the context of ecodesign, the emerging area of design for sustainable behavior (DfSB) specifically aims at designing solutions for reducing the impact caused by the way in which users interact with products (Lilley 2009; Zachrisson and Boks 2012b). As in LCA studies, research in DfSB has become increasingly aware of the need to include variation in how people use products and advocates for a better integration of existing knowledge of human decision making with sustainable product design (Zachrisson and Boks 2012b). Below, we highlight important behavioral aspects and recent interesting studies on sustainable behavior. This overview is not meant to be comprehensive, as it specifically focuses on those cognitive aspects underlying human decision making that, in our opinion, can suggest concrete intervention for behavior change in the context of sustainable product design and policy interventions.

\subsection{Temporal discounting and the importance of feedback}

A major hallmark of sustainable behavior is that its benefits will mainly become evident in the future. Therefore, it is important to understand how people decide when some or all of the outcomes of their decisions are going to happen in the future. Outcomes that materialize in the future tend to be perceived as less important than the ones that occur immediately, and people differ from each other in how much they care about future outcomes. Temporal discounting is important for a wide range of behaviors with environmental impact. The reason for this is twofold: the environmental benefits of choosing an energy saving option today are perceived as less important 
simply because they are distant in time and moreover somewhat uncertain. This may have important implications especially for interventions aimed at encouraging the use of more efficient (but with a higher purchase price) house appliances (Newell and Siikamäki 2013). Secondly, even the monetary costs of paying for energy consumption is typically incurred temporally separated from consumption. Using the car is not associated with paying at the moment it is used, but only when the car needs fueling up. Likewise, individuals pay for their energy and resource consumption in the household in the form of their utility bill, which comes at most every month. This temporal separation makes it less likely that people will reduce their energy consumption in order to save money, because the delayed money savings are simply not so relevant at the time of consumption. The use of feedback allows connecting behavior to its material consequences (e.g., financial consequences) by signaling it more closely in time, thus breaking down the effect of delay.

Often individuals do not receive feedback on the impact of each individual behavior. How much of a utility bill is attributable to which specific action is usually not clear. A recent field experiment demonstrates that a tighter and more specific coupling of feedback to the behavior can help to decrease consumption (Tiefenbeck et al. 2013). A device measuring water temperature and flow in the shower was installed in 700 households. In one third of the households, the device only indicated the current water temperature, but did not provided feedback on consumption. This group served as the control condition. In the other households, the device displayed real-time information about water and energy use. Compared to control households, the households receiving feedback decreased water and energy use in the shower by about $20 \%$ as soon as the intervention was started, and this effect was sustained over 2 months, suggesting that the effect did not wear off in this period. Thus, linking costs with actual consumption represents a promising avenue for design intervention behavior change aimed at reducing the impact of a product. For example, this might translate into providing positive/negative feedback (e.g., amount of energy consumed) to the user when interacting with the product (Wilson et al. 2015).

\subsection{Default and status quo effects}

Another robust finding in behavioral studies is that people are strongly influenced by defaults. That is, if one of the available options is labeled as the default that will be implemented unless an active choice is made and another option is selected, this default option will be chosen much more often (Kahneman et al. 1991). A related phenomenon is the status quo bias: people are unlikely to make changes to an existing state or condition even when this would be beneficial. A variety of factors is thought to contribute to this: people may perceive the availability of a default as a signal that this option is superior to the others or that many other people will chose this option. Also, people are generally reluctant to change the status quo because they pay more attention to the advantages of what they have, than to the advantages of the alternative options. Lastly, people can simply be inattentive or even have a strong preference to avoid making a decision, in which case they will also welcome the default option. A natural field experiment at a large Swedish University found that the adoption of a double-sided printing default setting in the printing machines led to a substantial reduction, with a significant and immediate effect in the form of a $15 \%$ drop in paper consumption, and with that effect staying stable over time. Notably, the effect of the double-sided default has been found to be far larger than that of a $10 \%$ tax on paper products, which would produce a mere $2 \%$ reduction (Egebark and Ekström 2013). Therefore, products which include green default settings are more likely to result in reducing the environmental impact of the use phase.

\subsection{The influence of social context}

Human behavior is best understood within a social context, as it is often shaped by the presence and behavior of others. This means that drivers of behaviors are not only explained by people pursuing their own self interest, but also by their social preferences (such as reciprocity, altruism) and self-image concerns (such as reputation, self-respect and status) and perceived behavior of others (social norm). Therefore, the social context is another extremely relevant aspect of proenvironmental behavior.

While the integrity of the environment and the availability of natural resources depend on the contribution of each single individual, the benefits of these are shared by everyone, irrespective of their contribution. That is, they represent a "social dilemma". Recycling of household waste is an example for this: collecting and recycling takes effort and commitment by the individual, but the resulting environmental benefits are enjoyed by everyone in the community and thus also by those who do not recycle. Likewise, the environmental impacts of individuals not recycling their waste are also shared equally by everyone. Thus, environmentally relevant behaviors impose externalities on society. In this condition, if individuals simply maximize their own benefits, pro-environmental behaviors are unlikely to occur. Yet, moral and social motives can influence people's willingness to reduce negative externalities they impose on others.

A large amount of research on social dilemmas highlights various ways to increase pro-social behavior. For example, Alpizar et al. (2008) have found that people contributed higher amounts to the preservation of a national park if they received a small gift before deciding on their contributions. A large field experiment on carbon offset found that bus customers who were asked to contribute to a carbon-offsetting scheme 
while buying their tickets contributed more when the company offered to match their contribution (Kesternich et al. 2014). Thus, it appears that inducing feelings of reciprocity and fairness can in principle increase pro-environmental behavior.

People might also act environmentally friendly not (only) because they are intrinsically motivated to do so, but because they care about the way they are perceived by others. Receiving information about the behavior of others can be a strong personal motivation to spur compliance with environmentally responsible behavior. For example, a recent study has shown that reputation influenced the adoption of an energy program that actively reduced individuals' energy use during periods of high electricity demand, so to protect the entire system from blackouts. Individuals were more likely to adopt the program if their behavior could be observed by others (e.g., signing up with their names on sheets provided in communal spaces), and the effect was stronger for people living in apartment buildings, where interactions with their neighbors are more likely to occur compared to individual homes (Yoeli et al. 2013). Also, people generally perceive the behavior of the majority as setting the norm for acceptable behavior. This is an important insight for framing messages designed to influence people's behavior. If possible, it is preferable to highlight that a majority engages in a desirable behavior such as recycling, rather than highlighting that some people fail to do so. Goldstein et al. (2008) applied social comparison drivers in a field experiment in hotels showing that messages like "the majority of guests reuse their towels" encouraged more hotel guests to do the same compared to messages simply stressing the environmental benefits of towel reuse. Interestingly, this effect was even stronger when the message was referring more closely to the guests' immediate context, such as "the majority of guests in this room reuse their towels", possibly leading to a closer identification of the hotel guests with the majority. This motive has also been successfully employed in a field experiment investigating an energy conservation program. Using data on energy usage from 600,000 households, it was one of the largest randomized field experiments in history. OPOWER mailed home energy report letters that compared a household's energy consumption to that of similar neighbors. These letters include messages like: "Last month you used $15 \%$ less electricity than your efficient neighbors". The average treatment effects of OPOWER's conservation programs ranged from 1.4 to $3.3 \%$ of baseline usage, with a mean reduction in energy consumption of $2.0 \%$ (Allcott 2011; Allcott and Rogers 2014). The cost-efficiency of this conservation program compared favorably with other energy efficiency programs (Allcott and Mullainathan 2010). As highlighted in Schultz et al. (2007), caution should be paid in designing social norm interventions so that they do not reduce pro-environmental behaviors of those that are already "above" the norm. Taken together, studies on social norms suggest that designers might envisage products that enable interactions between users, thereby allowing for feedback based on social comparison and eliciting feelings of reciprocity and fairness. This might be more feasible for those appliances that automatically collect information on user behavior (e.g., sensors classifying daily living activities).

\subsection{The influence of habits and environmental stimuli}

A further important insight on behavior in the context of sustainability is that there is a strong influence of habits. Habits are learned behavioral patterns that are performed without much conscious deliberation and instead strongly controlled by the stimulus environment (Dezfouli et al. 2014; Orbell and Verplanken 2015). Indeed, actions such as turning the light on/off, disposing waste, running the bath or shower are often done in a repetitive and almost unconscious way. Using data from a field experiment in Sweden, Eriksson et al. (2008) suggested habitual behavior to be a key factor in choosing means of transport. While habits are useful to free up cognitive resources for more important decisions, they may become particularly problematic when dealing with conditions for behavior change.

Environmental stimuli play an important role in maintaining habitual behavior patterns, and as such they could be employed also to change them. For example, several studies have found that people are more likely to establish new behavior patterns after moving to a new environment (Bamberg 2006; Dolnicar and Grun 2009; Walker et al. 2014). In an attempt to decrease food waste in the well-defined environment of hotel buffets, Kallbekken and Sælen (2013) have identified some simple changes to decrease waste caused by guests loading too much food on their plate. Using a large number of comparable hotels, the researchers were able to systematically test and compare two interventions to a control group. Simply by using smaller plates, people were better able to estimate the quantity of food that they wanted and reduced food waste by $20 \%$. The same effect was achieved by explicitly inviting people to visit the buffet repeatedly, rather than taking a lot at once. This finding is in line with the observation that people have difficulties predicting their own visceral states, in this case how much food they actually need.

Environmental stimuli (such as the way a particular product is designed) can also stimulate a particular behavior without a history of learning and habit formation if they naturally enable or encourage a particular behavior, a concept known as "affordances" (Gibson 1979). This might be particularly relevant for product design, where modifications in the way affordances (e.g., possibility of interacting with the product) are created can be used to design products that support environmentally friendly behavior (Srivastava and Shu 2013a).

The effect of environmental stimuli on choices has also been successfully applied to increase the proportion of healthy food chosen and consumed in canteens. Making healthier options more easily accessible than less healthy options 
consistently increased the choice of healthier foods (Hanks et al. 2013). Similar techniques could be tried towards decreasing meat consumption. A recent survey from the Netherlands suggests that, other than commonly thought, a sizable majority of people do not have a strong preference to consume meat frequently (Dagevos and Voordouw 2013). This group of people might be receptive to small changes in the choice environment and choose less environmentally impacting alternatives if this was made easier or more appealing.

\subsection{Limits in information processing}

Rational models of human decision making assume that individuals will understand and process all the available information. However, in the face of complex decisions and limited attention and time, people tend to use so-called "heuristics", which are smart rules of thumbs, to simplify the problem. The use of such heuristics is particularly important when understanding how users react to information on the energy consumption and environmental impact of a product. This might well explain why in the field of sustainable consumption attempts to increase consumer knowledge through provision of information have shown little impact on behavior (Davies et al. 2002; Gardner and Stern 2002; Pedersen and Neergaard 2006; Moisander 2007). Moreover, if products differ on several dimensions such as energy efficiency, pollution, durability, and price, it is unlikely that the decision maker will integrate all of these into his choice. Rather, he will attend to a selection of these, for example the ones he understands best or considers most important. For example, in a study of alternative labeling schemes for energy-efficiency appliances, labels providing simple information on the economic value of saving energy represented the most important element guiding more cost-efficient purchases, while the addition of further information (e.g., on carbon dioxide emission or energy use) had little effect (Newell and Siikamäki 2013).

Complex choices can lead to information overload and ultimately demotivation ("choice overload", (Chernev et al. 2015). Under a "too many choices" condition, individuals become overwhelmed by the number of options and may accept even more the standard option. It is thus important to present relevant information as simple and intuitive as possible: for example, it has been shown that the most common US measure of fuel efficiency, namely the "miles-per-gallon" measure, is not intuitive (Larrick and Soll 2008). As a result, this measure may lead to a significant underestimation of benefits of replacing most inefficient vehicles. By contrast, knowing that people are more likely to understand if a continuous measure (e.g., water use) is broken down into discrete unit, products that present information on resource use in discrete units (e.g., in cups), might work more effectively in reducing resource consumption (Srivastava and Shu 2013b).

\section{Conceptual model of the integration between behavioral science, LCA, and ecodesign}

Building from the overview on BS presented above, it is clear that there are various aspects of LCA and ecodesign that could benefit from a better understanding of human behavior, in particular in the interaction with products in the use phase. In fact, it has been argued that, without attending to consumption patterns and behaviors, efforts towards more sustainability will be undermined (Throne-Holst et al. 2007; Peattie 2010). For this purpose, in the following we describe specifically how inputs from behavioral science may be valuable for LCA (and ecodesign). Figure 1 presents a conceptual scheme of the potential contribution, while Table 1 explores the possible integration of a behavioral approach within the various steps of LCA, providing examples of where this has been already discussed and applied in literature.

Firstly, for a given product $\mathrm{A}$, the use phase modeling is usually based on assumptions or on average user behavior. This could be linked to e.g., technical specification of the manufacturers or average assumptions on use or on laboratory test on the product (Daae and Boks 2015). Behavioral studies may be used to the following: (i) identify more realistic user scenarios (e.g., exploring best case, worst case, gender- or culture-related differences, clustering the users etc.) (ii) define the share of the considered users, in terms of likelihood to be representative of one of the behaviors (e.g., $20 \%$ behavior 1 , $30 \%$ behavior 2 , etc.), (iii) explore possibility and likelihood of occurrence of improved behaviors (e.g., using the same product but behaving differently to reduce impact, e.g., same car but driving less, same fridge but all the maintenance done properly). From the LCA perspective, the different behaviors may lead to variability in the impacts, thus highlighting which behavior is potentially less impacting.

Secondly, under more realistic user scenarios, the ranking of two compared products may change (e.g., the better product under one set of behavioral assumptions could become less environmentally favorable under a different scenario). This may lead e.g., to different emissions or to impacts emerging from different categories.

LCA results accounting for different behaviors and possible behavior changes (e.g., likelihood and typologies of improved behaviors) are key elements for informing ecodesign of an improved product $\mathrm{B}$. The latter could be named "behavioral-driven eco-innovation", accounting for if and how a behavior may change.

Indeed, product $\mathrm{B}$, as result of attempts to reduce hotspot impacts as identified by LCA and of behaviorally driven insights, could be again tested under different user scenarios. Often improved products are associated to rebound effects, which are discussed in the literature but not always systematically modeled (e.g., Thiesen et al. 2008; Druckman et al. 2011; Vivanco and van der Voet 2014). Again behavioral science 


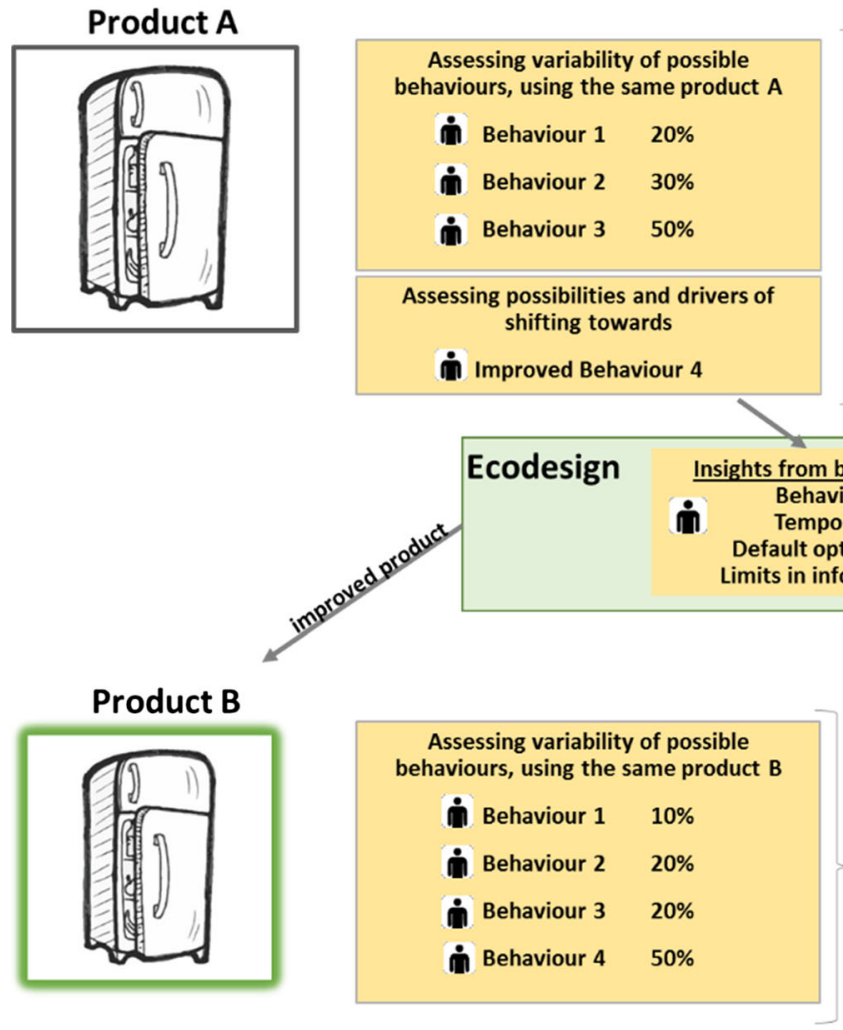

Fig. 1 Conceptual scheme of the mutual interaction between behavioral science, life cycle assessment, and ecodesign. The yellow boxes refer to contribution of behavioral science to use phase modeling in LCA and improvement definition in ecodesign. Behavioral science may help identifying more realistic user scenarios and sets of behaviors (behavior $1,2,3)$ and their possible share among a population, as well as exploring

could be of support in modeling rebound effects related to behavior (Nässén and Holmberg 2009; Freire-González 2011).

Table 1 illustrates for each LCA step how accounting for behavioral aspects may improve the realism of the assessment including: goal and scope step (decision context, system boundaries, functional unit), life cycle inventory, life cycle impact assessment, communication of the results, and input for ecoinnovation and ecodesign. Examples from the LCA context are usually focusing on one aspect, whereas theoretically BS could be integrated in each step systematically.

\section{Discussion and conclusions}

Improving the modeling of consumer choice and behavior is crucial for improving realism of life cycle assessment and supporting ecodesign. Behavioral science may support this improvement by means of giving insights for enriching modeling scenarios, accounting for drivers of behavior variability, and assessing drivers of changes. A variety of research methods is available for observing, measuring, and predicting behavior, and these may help in defining clusters of behavior,

\section{Life cycle assessment}



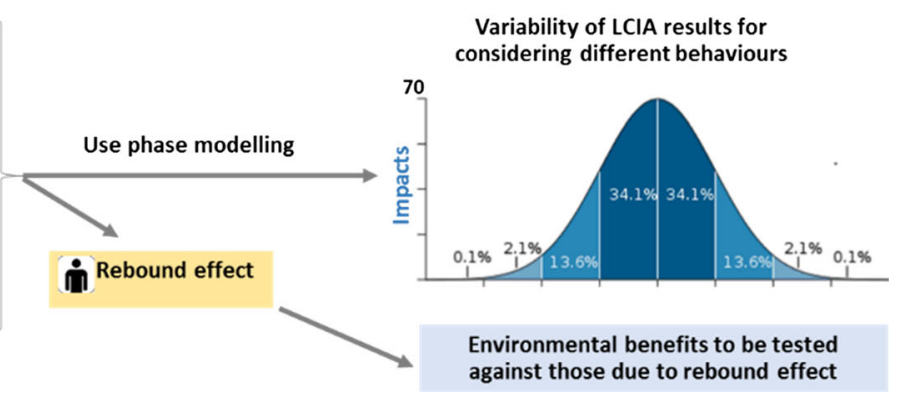

drivers of new/improved behaviors (behavior 4). Behavioral science may also inform ecodesign on specific drivers for behavior change (e.g., setting the environmentally preferred options as default option in a product). Moreover, behavioral science may help assessing possible options related to rebound effects

likelihood of occurrence of improved behavior, possibility, and direction of behavioral spillover effects.

As discussed in the previous sections, one of the main limitations with respect to applying behavioral insights in LCA studies is given by the effort needed to collect primary data. When time and money is limited, it might be difficult to include a thorough assessment of the various behaviors affecting the use phase and model it accordingly. Nevertheless, even when resources do not allow for collection of primary behavioral data, existing survey projects and insights from behavioral science can still help to replace largely untested assumption of user behavior with empirically supported ones. Given possible limitations due to resource and time availability, LCA and behavioral science may jointly explore the use of proxy indicators for analyzing - indirectly — consumer typologies as well as future trends in consumption and behavior e.g., through assessing available studies and statistics on income, demography, cultural and geographical-related aspects. Moreover, LCA and BS may jointly explore how to improve collecting information feedback during consumption. An option could be investigating the role of social networks and new ways for transdisciplinary interaction with stakeholders to 
Table 1 Potential contribution of behavioral science (BS) within steps of LCA and as input to communication and ecodesign

Behavioral science support to LCA studies in each LCA step

Goal and scope Decision context

System boundary

Functional unit

Scenarios under assessment and assumptions on user behavior

LCI

Data collecting

LCIA

Impact assessment

Communications

Presentation of LCA results, labeling

Potential improvement Feedback to ecodesign
Helping in defining assumptions for the specific decision context, also including culturalspecific or social-context-specific aspects

System boundaries may change, e.g., if there is the need of moving from product to functions of the product, meaning that the product is used for answering a need and this need may be fulfilled with product/services etc. BS may help moving from product orientation to function orientation in assessing the way consumer answer to his need. Moreover, including the assessment of rebound effects (Girod et al. 2011; Vivanco and van der Voet 2014) may imply the system expansion.

Goedkoop et al. (1998) and Goedkoop (1999) advocated for determining the functional unit based on the observed consumer and producer's behavior, rather than arbitrarily. By using observed behavioral data, two main outcomes arise: first, changes in demand due to the direct rebound effect may be incorporated and second, changes in different ancillary product systems can be assessed, offering a broader picture to potentially assess other causal effects. The functional unit indeed should be based on insight of variability of different behavior, based on behavior measuring.

Several scenarios could be run in order to assess variability in the results (as estimate of the uncertainty of the results) as well as exploring and identifying condition which may minimize the impacts. Assumption on life span of a product, typologies of uses etc. should be based on clusters of behaviors. Regarding clustering of use, an example could be the clustering of users' behavior based on being a "hero", "antihero" or anarchist (Autio et al. 2009) as well as framing different perceptions and associated consumers profiles (e.g. Gatersleben et al. 2002) including ecological behaviors (Kaiser et al. 2003).

Additionally, differences in use phase could be linked to variability in behavior due to, e.g., lifestyle (Heinonen and Junnila 2011; Bin and Dowlatabadi 2005), geographical context (Schlegel et al. 2012), income (Girod and de Haan 2010), age and demographic aspects (Zagheni 2011) etc.

BS may equally support definition of future scenarios, helping framing future consumption trends (e.g., Girod et al. 2013a; Erickson et al. 2012)

Using BS results to assess how the inventory should be built and be modified under different scenarios of use. This is again linked with availability of information on different possible behaviors.

Examples of this are related, e.g., to the emission profile of different driving behaviors (Rangaraju et al. 2015; Girod et al. 2013b)

Behavior-related aspects that may imply higher or lower likelihood to be exposed in the use phase. Indeed, examples exist on for variability in exposure, exposure duration, use of preventive measures e.g., in the indoor impact assessment under development within LCA (Jolliet et al. 2015; Golsteijn et al. 2014)

BS may help in identifying the message and most effective ways to deliver communication of LCA results (see for example Waechter et al. 2015). This may also support understanding how the LCA results are perceived (Tobler et al. 2011) and or how LCA-based labeling could be more effective (Röös and Tjärnemo 2011)

BS may support the decision on whether (and how) improving the products (e.g., default options as the greener one, improving users' awareness through feedback).

This could be based on evidence of possibilities for behavioral changes (e.g. Tobler et al. 2011; Jones and Kammen 2011)

Studies on how the behavior of a user is affected by the design of a product are increasingly available (see e.g. the list provided by Daae and Boks 2015 on DfSB) asn the example of influence of packaging attributes on consumer behavior (Wikström et al. 2014). Other studies such as those on influencing factors and mitigation prospects (Zhang et al. 2015) as well as of persuasive technology to encourage sustainable behavior (Midden et al. 2008) capture real-life use of products (e.g., as done in marketing studies).

Additionally, wherever consumer behavior in the use phase significantly affects the overall impact of a product, there is scope to explore options for behavior change, supporting ecoinnovation and ecodesign. There is a range of welldocumented behavioral patterns that can in principle be used by product designers and policy makers to facilitate sustainable behavior, including temporal discounting and the importance of feedback to the users, the power of default options, 
and the influence of the social context and of environmental stimuli. However, although behavioral interventions like the one summarized in Section 5 have been shown effective in altering behavior towards more sustainable choices, evaluations are performed usually within a relatively short time frame and rarely consider other behaviors than the target behavior. Moreover, the drivers that promote the adoption of a certain behavior might be different from those involved in its long-term maintenance. These effects are potentially problematic from an LCA perspective. If behavior is not persistently changed through the intervention, the value of the intervention will be limited. People might get used to the intervention and effects may wear off. For instance, when investigating the effect of social comparisons on energy consumption levels, Allcott and Rogers (2014) found that consumers' response to the intervention was quite volatile over time, indicating that long follow-up periods are necessary to fully appreciate the effect of an intervention.

Similarly, if target behaviors are too narrowly defined (e.g., shower use), it will be difficult to know whether the intervention affects also other behaviors. Human behavior is fundamentally complex, people may have different reason to act (or not) in a sustainable way, and the choices adopted in one specific domain may have different consequences in other (un)related domains (e.g., spillover effects). Such spillover effects may either increase or offset the effects achieved with the intervention. In principle, LCA allows for the integration of such indirect effects, and promising methods have been suggested (Thiesen et al. 2008; Girod et al. 2011). For example, the adoption of different functional units in terms of satisfying a particular need could represent an interesting alternative way of modeling indirect effects (Hofstetter et al. 2006). However, correctly modeling rebound effects is not straightforward and high levels of complexity might constrain the likelihood of achieving relevant responses through behavior change.

Finally, when attempting to re-design products in order to facilitate pro-environmental behavior, it should be considered that certain behaviors can be hard to change (Stern 2011), and that systematic testing of interventions in the specific context is required in order to understand which intervention is most effective and what is the magnitude of the effect. Spaargaren and Van Vliet (2000) suggest that adoption of sustainable behavior is moderated by a compromise between a lifestyle aspiration of consumers (depending upon their sense of identity, values and circumstances) and the nature of public and commercial provisioning systems that meets their needs. This highlights the fact that if external constrains (e.g., sociocultural factors) are not properly taken into account when designing opportunities for behavior change, the effect of such interventions can be of limited (if any) impact. Moreover, any intervention promoting lower-impact choices and behaviors should complement both "hard" traditional regulation and "soft" behavioral interventions. This would allow balancing control and freedom of choice when engineering solutions for sustainable behavior (Pettersen and Boks 2008). Again, this requires capitalizing on existing knowledge on consumerproduct interaction (e.g., the data and insights collected in the context of small-scale studies in DfSB, reviewed by Daae and Boks 2015).

To conclude, the joint effort with behavioral scientists could provide important (behavioral) insights and a set of innovative methodological tools to evaluate the efficacy of behavior change interventions within the context of LCA and ecoinnovation, as depicted in Fig. 1 and Table 1. Future research in LCA should aim at better understanding how to streamline and systematize the use of behavioral insights from goal and scope definition, up to scenario definition, inventory development, impact assessment, and communication. Behavioral studies may be helpful at both micro (product) and macro (e.g. policy) scales. Eventually, LCA results including analysis of uncertainty and variability due to behavior may help design better products by industry as well as helping policy makers to define requirements for product performance related to the use phase.

\section{Compliance with ethical standards}

Conflict of interest The authors declare that they have no competing interests.

Open Access This article is distributed under the terms of the Creative Commons Attribution 4.0 International License (http:// creativecommons.org/licenses/by/4.0/), which permits unrestricted use, distribution, and reproduction in any medium, provided you give appropriate credit to the original author(s) and the source, provide a link to the Creative Commons license, and indicate if changes were made.

Open Access This article is distributed under the terms of the Creative Commons Attribution 4.0 International License (http:// creativecommons.org/licenses/by/4.0/), which permits unrestricted use, distribution, and reproduction in any medium, provided you give appropriate credit to the original author(s) and the source, provide a link to the Creative Commons license, and indicate if changes were made.

\section{References}

Ajzen I (1991) The theory of planned behavior. Organ Behav Hum Decis Process 50:179-211

Allcott H (2011) Social norms and energy conservation. J Public Econ 95: 1082-1095

Allcott H, Mullainathan S (2010) Behavior and energy policy. Science 327:1204-1205

Allcott H, Rogers T (2014) The short-run and long-run effects of behavioral interventions: experimental evidence from energy conservation. Am Econ Rev 104:3003-3037

Alpizar F, Carlsson F, Johansson-Stenman O (2008) Anonymity, reciprocity, and conformity: Evidence from voluntary contributions to a national park in Costa Rica. J Public Econ 92(5):1047-1060 
Armitage CJ, Conner M (2001) Efficacy of the theory of planned behaviour: a meta-analytic review. Br J Soc Psychol 40:471-499

Autio M, Heiskanen E, Heinonen V (2009) Narratives of 'green' consumers - the antihero, the environmental hero and the anarchist. J Consum Behav 8(1):40-53

Bamberg S (2006) Is a residential relocation a good opportunity to change people's travel behavior? Results from a theory-driven intervention study. Environ Behav 38:820-840

Bamberg S, Schmidt P (2003) Incentives, morality, or habit? Predicting students' car use for university routes with the models of Ajzen, Schwartz, and Triandis. Environ Behav 35:264-285

Bamberg S, Möser G (2007) Twenty years after Hines, Hungerford, and Tomera: a new meta-analysis of psycho-social determinants of proenvironmental behaviour. J Environ Psychol 27:14-25

Bamberg S, Fujii S, Friman M, Gärling T (2011) Behaviour theory and soft transport policy measures. Transp Policy 18:228-235

Bennadji A, Laing R, Gray D (2015) Urban planning and climate change mitigation: using virtual reality to support the design of a university master plan extension. In: Silva CN (ed) Emerg. Issues, Challenges, Oppor. Urban E-Planning. IGI Global, p 380

Bin S, Dowlatabadi H (2005) Consumer lifestyle approach to US energy use and the related CO 2 emissions. Energ Policy 33(2):197-208

BIO Intelligence Service (2012) Study on different options for communicating environmental information for products, Final report prepared for the European Commission - DG Environment

Carlsson F, Johansson-Stenman O (2012) Behavioral economics and environmental policy. Ann Rev Resour Econ 4:74-99

Carsten O, Jamson AH (2011) Driving simulators as research tools in travel psychology. Handb Traffic Psychol

Chen C, Mokhtarian PL (2006) Tradeoffs between time allocations to maintenance activities/travel and discretionary activities/travel. Transportation (Amst) 33:223-240

Chernev A, Böckenholt U, Goodman J (2015) Choice overload: a conceptual review and meta-analysis. J Consum Psychol 25:333-358

Cohen M, Brown H, Vergragt P (2010) Individual consumption and systemic societal transformation: introduction to the special issue. Sust Pract Policy 6:6-12

Corral-Verdugo V (1997) Dual realities of conservation behavior: self reports vs observations of re-use and recycling behavior. J Environ Psychol 17:135-145

Croson R, Treich N (2014) Behavioral environmental economics: promises and challenges. Environ Resour Econ 58:335-351

Daae J, Boks C (2015) Opportunities and challenges for addressing variations in the use phase with LCA and design for sustainable behaviour. Int J Sustain Eng 8:148-162

Dagevos H, Voordouw J (2013) Sustainability and meat consumption: is reduction realistic? Sustain Sci Pract Policy 9:60-69

Davies J, Foxall GR, Pallister J (2002) Beyond the intention-behaviour mythology: an integrated model of recycling. Mark Theory 2:29 113

Dezfouli A, Lingawi NW, Balleine BW (2014) Habits as action sequences: hierarchical action control and changes in outcome value. Philos Trans R Soc Lond B Biol Sci 369:20130482

Dolan P, Galizzi MM (2015) Like ripples on a pond: behavioral spillovers and their implications for research and policy. J Econ Psychol 47:116

Dolnicar S, Grun B (2009) Environmentally friendly behavior: can heterogeneity among individuals and contexts/environments be harvested for improved sustainable management? Environ Behav 41: 693-714

Druckman A, Chitnis M, Sorrell STJ (2011) Missing carbon reductions? Exploring rebound and backfire effects in UK households. Energy Policy 39:3572-3581

Eberle R, Franze HA (1998) Modelling the use phase of passenger cars in LCI. SAE Tech Pap. doi:10.4271/982179
Egebark J, Ekström M (2013) Can indifference make the world greener? IFN Work. Pap

Eriksson L, Garvill J, Nordlund AM (2008) Interrupting habitual car use: the importance of car habit strength and moral motivation for personal car use reduction. Transp Res Part F Traffic Psychol Behav 11: $10-23$

Erickson P, Chandler C, Lazarus M (2012) Reducing greenhouse gas emissions associated with consumption: A methodology for scenario analysis. Stockholm Environment Institute. Working Paper. 5

Falk A, Becker A, Dohmen T et al (2013) An experimentally validated preference survey module. CESifo Area Conf Behav Econ

Fehr E, Fischbacher U (2004) Social norms and human cooperation. Trends Cogn Sci 8:185-190

Freire-González J (2011) Methods to empirically estimate direct and indirect rebound effect of energy-saving technological changes in households. Ecol Modell 223:32-40

Gabbard JL, Swan JE (2008) Usability engineering for augmented reality: employing user-based studies to inform design. IEEE Trans Vis Comput Graph 14:513-525

Gardner G, Stern P (2002) Environmental problems and human behavior. Allyn \& Bacon

Gatersleben B, Steg L, Vlek C (2002) Measurement and determinants of environmentally significant consumer behavior. Environ Behav 34(3):335-362

Gibson JJ (1979) The ecological approach to visual perception. Houghton Mifflin Harcourt

Girod B, De Haan P (2010) More or better? A model for changes in household greenhouse gas emissions due to higher income. J Ind Ecol 14(1):31-49

Girod B, de Haan P, Scholz RW (2011) Consumption-as-usual instead of ceteris paribus assumption for demand. Int J Life Cycle Assess 16: $3-11$

Girod B, Van Vuuren DP, Hertwich EG (2013a) Global climate targets and future consumption level: an evaluation of the required GHG intensity. Environ Res Lett 8(1):14016

Girod B, van Vuuren DP, de Vries B (2013b) Influence of travel behavior on global CO 2 emissions. Transp Res A Policy Pract 50:183-197

Goedkoop MJ (1999) Product service systems, ecological and economic basics. Ministry of Housing, Spatial Planning and the Environment, Communications Directorate, The Hague, The Netherlands

Goedkoop M, Te Riele H, Van Halen C, Rommens P (1998) Product service combinations. Proc. 3rd Int. Conf. Ecobalance, Tsukuba. pp 25-27

Goldstein NJ, Cialdini RB, Griskevicius V (2008) A room with a viewpoint: using social norms to motivate environmental conservation in hotels. J Consum Res 35:472-482

Golsteijn L, Huizer D, Hauck M, van Zelm R, Huijbregts MA (2014) Including exposure variability in the life cycle impact assessment of indoor chemical emissions: the case of metal degreasing. Environ Int $71: 36-45$

Gowdy JM (2008) Behavioral economics and climate change policy. J Econ Behav Organ 68:632-644

Gubbi J, Buyya R, Marusic S, Palaniswami M (2013) Internet of Things (IoT): a vision, architectural elements, and future directions. Futur Gener Comput Syst 29:1645-1660

Haldi F, Robinson D (2011) Modelling occupants' personal characteristics for thermal comfort prediction. Int J Biometeorol 55:681-694

Hammitt JK (2013) Positive versus normative justifications for benefitcost analysis: implications for interpretation and policy. Rev Environ Econ Policy 7:199-218

Hanks AS, Just DR, Wansink B (2013) Smarter lunchrooms can address new school lunchroom guidelines and childhood obesity. J Pediatr $162: 867-869$

Hanssen OJ (1998) Environmental impacts of product systems in a life cycle perspective. J Clean Prod 6:299-311 
Heinonen J, Junnila S (2011) A carbon consumption comparison of rural and urban lifestyles. Sustainability 3(8):1234-1249

Hellweg S, Mila I, Canals L (2014) Emerging approaches, challenges and opportunities in life cycle assessment. Science 344(6188):11091113

Hertwich EG (2005) Consumption and the rebound effect. J Ind Ecol 9: $85-98$

Hertwich EG, Roux C (2011) Greenhouse gas emissions from the consumption of electric and electronic equipment by Norwegian households. Environ Sci Technol 45(19):8190-8196

Hofstetter P, Madjar M, Ozawa T (2005) The fallacy of ceteris paribus and real consumers - An attempt to quantify rebound effects. Sustain Consum Contrib Res 48-63

Hofstetter P, Madjar M, Ozawa T (2006) Happiness and Sustainable Consumption. Psychological and physical rebound effects at work in a tool for sustainable design. Int J Life Cycle Assess 11:105-115

Huijbregts MAJ (1998) Application of uncertainty and variability in LCA. Int J Life Cycle Assess 3:273-280

Humbert S, Loerincik Y, Rossi V et al (2009) Life cycle assessment of spray dried soluble coffee and comparison with alternatives (drip filter and capsule espresso). J Clean Prod 17:1351-1358

Jackson T (2005) Motivating sustainable consumption. Sustain Dev Res Netw 29:30

Johnsson A (1999) Including the use phase in LCA of floor coverings. Int J Life Cycle Assess 4:321-328

Jolliet O, Ernstoff AS, Csiszar SA, Fantke P (2015) Defining product intake fraction to quantify and compare exposure to consumer products. Environ Sci Technol 49(15):8924-8931

Jones CM, Kammen DM (2011) Quantifying carbon footprint reduction opportunities for US households and communities. Environ Sci Technnol 45(9):4088-4095

Kahneman D, Knetsch JL, Thaler RH et al (1991) Anomalies: the endowment effect, loss aversion, and status quo bias. J Econ Perspect 5:193-206

Kaiser FG, Doka G, Hofstetter P, Ranney MA (2003) Ecological behavior and its environmental consequences: a life cycle assessment of a self-report measure. J Environ Psychol 23(1):11-20

Kallbekken S, Sælen H (2013) "Nudging" hotel guests to reduce food waste as a win-win environmental measure. Econ Lett 119:325-327

Kesternich M, Löschel A, Römer D (2014) The long-term impact of matching and rebate subsidies when public goods are impure: Field experimental evidence from the carbon offsetting market. Working paper

Klöckner CA, Blöbaum A (2010) A comprehensive action determination model: toward a broader understanding of ecological behaviour using the example of travel mode choice. J Environ Psychol 30: 574-586

Koehler A, Wildbolz C (2009) Comparing the environmental footprints of home-care and personal-hygiene products: the relevance of different life-cycle phases. Environ Sci Technol 43:8643-8651

Laitala K, Klepp IG, Boks C (2012) Changing laundry habits in Norway. Int J Consum Stud 36:228-237

Langevin J, Gurian PL, Wen J (2015) Tracking the human-building interaction: a longitudinal field study of occupant behavior in airconditioned offices. J Environ Psychol 42:94-115

Lanzini P, Thøgersen J (2014) Behavioural spillover in the environmental domain: an intervention study. J Environ Psychol 40:381-390

Larrick RP, Soll JB (2008) Economics. The MPG illusion. Science 320: 1593-1594

Lilley D (2009) Design for sustainable behaviour: strategies and perceptions. Des Stud 30:704-720

Logan B, Healey J (2006) Sensors to detect the activities of daily living. Conf Proc Ann Int Conf IEEE Eng Med Biol Soc IEEE Eng Med Biol Soc Ann Conf 1:5362-5365
Midden C, McCalley T, Ham, J, Zaalberg R (2008) Using persuasive technology to encourage sustainable behavior. Sustainability WS Pervasive

Milfont TL, Duckitt J (2010) The environmental attitudes inventory: a valid and reliable measure to assess the structure of environmental attitudes. J Environ Psychol 30:80-94

Moisander J (2007) Motivational complexity of green consumerism. Int J Consum Stud 31:404-409

Nässén J, Holmberg J (2009) Quantifying the rebound effects of energy efficiency improvements and energy conserving behaviour in Sweden. Energy Eff 2:221-231

Nederhof AJ (1985) Methods of coping with social desirability bias: a review. Eur J Soc Psychol 15:263-280

Newell RG, Siikamäki JV (2013) Nudging energy efficiency behavior: the role of information labels. NBER Work Pap Ser 43

O’Brien K, Olive R, Hus Y (2009) Life cycle assessment: Reusable and disposable nappies in Australia. 6th Australian LCA society conference, Melbourne, Australia

Ölander F, Thøgersen J (2014) Informing versus nudging in environmental policy. J Consum Policy 37:341-356

Orbell S, Verplanken B (2015) The strength of habit. Health Psychol Rev $1-7$

Peattie K (2010) Green consumption: behavior and norms. Annu Rev Environ Resour 35:195-228

Pedersen ER, Neergaard P (2006) Caveat emptor — let the buyer beware! Environmental labelling and the limitations of "green" consumerism. Bus Strateg Environ 15:15-29

Pettersen IN, Boks C (2008) The ethics in balancing control and freedom when engineering solutions for sustainable behaviour. Int J Sustain Eng 1:287-297

Pickett-Baker J, Ozaki R (2008) Pro-environmental products: marketing influence on consumer purchase decision. J Consum Mark 25:281293

Rangaraju S, De Vroey L, Messagie M, Mertens J, Van Mierlo J (2015) Impacts of electricity mix, charging profile, and driving behavior on the emissions performance of battery electric vehicles: a Belgian case study. Appl Energ 148:496-505

Reinhart CF (2004) Lightswitch-2002: a model for manual and automated control of electric lighting and blinds. Sol Energy 77:15-28

Röös E, Tjärnemo H (2011) Challenges of carbon labelling of food products: a consumer research perspective. Brit Food J 113(8):982-996

Saouter E, Hoof G, Feijtel TCJ, Owens JW (2002) The effect of compact formulations on the environmental profile of Northern European granular laundry detergents part II: life cycle assessment. Int J Life Cycle Assess 7:27-38

Schlegel M, Trutnevyte E, Scholz RW (2012) Patterns of residential heat demand in rural Switzerland. Build Res Inf 40(2):140-153

Schultz PW, Nolan JM, Cialdini RB et al (2007) The constructive, destructive, and reconstructive power of social norms. Psychol Sci 18: $429-434$

Scott AJ (2005) Real-life emissions from residential wood burning appliances in New Zealand

Shiffman S, Stone AA, Hufford MR (2008) Ecological momentary assessment. Annu Rev Clin Psychol 4:1-32

Shogren JF, Taylor LO (2008) On behavioral-environmental economics. Rev Environ Econ Policy 2:26-44

Solli C, Reenaas M, Strømman AH, Hertwich EG (2009) Life cycle assessment of wood-based heating in Norway. Int $\mathrm{J}$ Life Cycle Assess 14:517-528

Spaargaren G, Van Vliet B (2000) Lifestyles, consumption and the environment: the ecological modernization of domestic consumption. Environ Polit 9:50-76

Special Eurobarometer 416 Attitudes of European citizens towards the environment

Srivastava J, Shu L (2013a) Affordances and product design to support environmentally conscious behavior. J Mech Des 135:101006 
Srivastava J, Shu LH (2013b) Encouraging resource-conscious behavior through product design: the principle of discretization. J Mech Des 135(6):061002

Steinhorst J, Klöckner CA, Matthies E (2015) Saving electricity-for the money or the environment? Risks of limiting pro-environmental spillover when using monetary framing. J Environ Psychol 43: 125-135

Stern PC (2011) Contributions of psychology to limiting climate change. Am Psychol 66:303-314

Thaler RH, Sunstein CR (2008) Nudge. Yale University Press, New Haven

Thiesen J, Christensen TS, Kristensen TG et al (2008) Rebound effects of price differences. Int J Life Cycle Assess 13:104-114

Throne-Holst H, Stø E, Strandbakken P (2007) The role of consumption and consumers in zero emission strategies. J Clean Prod 15:1328-1336

Tiefenbeck V, Staake T, Roth K, Sachs O (2013) For better or for worse? Empirical evidence of moral licensing in a behavioral energy conservation campaign. Energy Policy 57:160-171

Tobler C, Visschers VH, Siegrist M (2011) Organic tomatoes versus canned beans how do consumers assess the environmental friendliness of vegetables? Environ Behav 43(5):591-611

Triandis HC (1977) Interpersonal behavior. Brooks-Cole, Monterey

Truelove HB, Carrico AR, Weber EU et al (2014) Positive and negative spillover of pro-environmental behavior: an integrative review and theoretical framework. Glob Environ Chang 29:127-138

Tukker A, Cohen MJ, Hubacek K, Mont O (2010) The impacts of household consumption and options for change. J Ind Ecol 14:13-30

Tversky A, Kahneman D (1974) Judgment under uncertainty: heuristics and biases. Science 185:1124-1131

Tversky A, Kahneman D (1981) The framing of decisions and the psychology of choice. Science 211:453-458

Vivanco D, van der Voet E (2014) The rebound effect through industrial ecology's eyes: a review of LCA-based studies. Int J Life Cycle Assess 19:1933-1947

Vivanco D, Kemp R, van der Voet E (2015) The relativity of eco-innovation: environmental rebound effects from past transport innovations in Europe. J Clean Prod 101:71-85

Waechter S, Sütterlin B, Siegrist M (2015) The misleading effect of energy efficiency information on perceived energy friendliness of electric goods. J Clean Prod 93:193-202

Walker I, Thomas G, Verplanken B (2014) Old habits die hard travel habit formation and decay during an office relocation. Environ Behav. doi:10.1177/0013916514549619
Webb T, Sheeran P (2006) Does changing behavioral intentions engender behavior change? A meta-analysis of the experimental evidence. Psychol Bull 132(2):249-268

Westhoek H, Lesschen JP, Rood T et al (2014) Food choices, health and environment: effects of cutting Europe's meat and dairy intake. Glob Environ Chang 26:196-205

Wikström F, Williams H, Verghese K, Clune S (2014) The influence of packaging attributes on consumer behaviour in food-packaging life cycle assessment studies - a neglected topic. J Clean Prod 73:100 108

Wilson GT, Bhamra T, Lilley D (2015) The considerations and limitations of feedback as a strategy for behaviour change. Int J Sustain Eng 8: 186-195

Woolridge AC, Ward GD, Phillips PS et al (2006) Life cycle assessment for reuse/recycling of donated waste textiles compared to use of virgin material: an UK energy saving perspective. Resour Conserv Recycl 46:94-103

Yoeli E, Hoffman M, Rand DG, Nowak M (2013) Powering up with indirect reciprocity in a large-scale field experiment. Proc Natl Acad Sci U S A 110(Suppl):10424-10429

Yun GY, Tuohy P, Steemers K (2009) Thermal performance of a naturally ventilated building using a combined algorithm of probabilistic occupant behaviour and deterministic heat and mass balance models. Energy Build 41:489-499

Zachrisson Daae J, Boks C (2014) Dimensions of behaviour change. J Des Res 12:145

Zachrisson J, Boks C (2012a) Exploring behavioural psychology to support design for sustainable behaviour research. J Des Res 10:50. doi: 10.1504/JDR.2012.046139

Zachrisson J, Boks C (2012b) Exploring behavioural psychology to support design for sustainable behaviour research. J Des Res 10:50-65

Zafiroglu A, Healey J, Plowman T (2012) Navigation to multiple local transportation futures. Proc. 4th Int. Conf. Automot. User Interfaces Interact. Veh. Appl. - AutomotiveUI '12. ACM Press, New York, p 139

Zagheni E (2011) The leverage of demographic dynamics on carbon dioxide emissions: does age structure matter? Demography 48(1): 371-399

Zhang X, Luo L, Skitmore M (2015) Household carbon emission research: an analytical review of measurement, influencing factors and mitigation prospects. J Clean Prod 103:873-883 